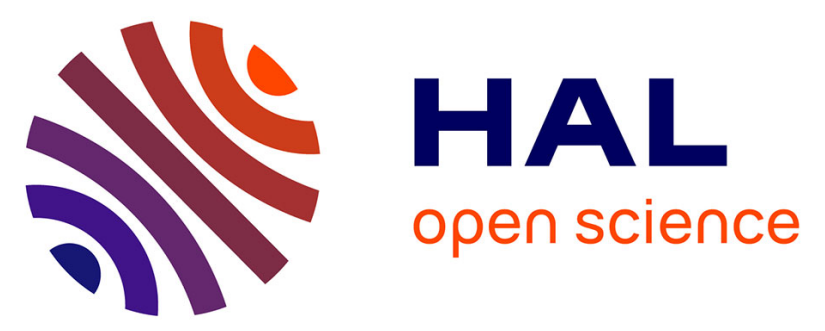

\title{
Fault Detection and Diagnosis in an Induction Machine Drive: A Pattern Recognition Approach Based on Concordia Stator Mean Current Vector
}

\author{
Demba Diallo, Mohamed Benbouzid, Denis Hamad, Xavier Pierre
}

\section{- To cite this version:}

Demba Diallo, Mohamed Benbouzid, Denis Hamad, Xavier Pierre. Fault Detection and Diagnosis in an Induction Machine Drive: A Pattern Recognition Approach Based on Concordia Stator Mean Current Vector. IEEE Transactions on Energy Conversion, 2005, 20 (3), pp.512-519. 10.1109/TEC.2005.847961 . hal-00526691

\section{HAL Id: hal-00526691 \\ https://hal.science/hal-00526691}

Submitted on 15 Oct 2010

HAL is a multi-disciplinary open access archive for the deposit and dissemination of scientific research documents, whether they are published or not. The documents may come from teaching and research institutions in France or abroad, or from public or private research centers.
L'archive ouverte pluridisciplinaire HAL, est destinée au dépôt et à la diffusion de documents scientifiques de niveau recherche, publiés ou non, émanant des établissements d'enseignement et de recherche français ou étrangers, des laboratoires publics ou privés. 


\title{
Fault Detection and Diagnosis in an Induction Machine Drive: A Pattern Recognition Approach Based on Concordia Stator Mean Current Vector
}

\author{
Demba Diallo, Member, IEEE, Mohamed El Hachemi Benbouzid, Senior Member, IEEE, Denis Hamad, and \\ Xavier Pierre
}

\begin{abstract}
The aim of this paper is to study the feasibility of fault detection and diagnosis in a three-phase inverter feeding an induction motor. The proposed approach is a sensor-based technique using the mains current measurement. A localization domain made with seven patterns is built with the stator Concordia mean current vector. One is dedicated to the healthy domain and the last six are to each inverter switch. A probabilistic approach for the definition of the boundaries increases the robustness of the method against the uncertainties due to measurements and to the PWM. In high-power equipment where it is crucial to detect and diagnose the inverter faulty switch, a simple algorithm compares the patterns and generates a Boolean indicating the faulty device. In low-power applications (less than $1 \mathrm{~kW}$ ) where only fault detection is required, a radial basis function (RBF) evolving architecture neural network is used to build the healthy operation area. Simulated experimental results on $0.3-$ and $1.5-\mathrm{kW}$ induction motor drives show the feasibility of the proposed approach.
\end{abstract}

Index Terms-Concordia transform, fault detection and diagnosis, induction motor, inverter, pattern recognition.

\section{INTRODUCTION}

$\mathbf{I}$ $\mathrm{N}$ many processes, electric machines are fed by a static converter [pumps, electric vehicle (EV), hybrid electric vehicle (HEV), etc.]. In EV or HEV, for example, because of the important investment cost and the high reliability for safety reasons, monitoring has become essential for maintenance purposes [1], [2]. The weakest part of the drive is the electronic-based components usually located in confined areas. So the diagnosis process focuses on the operation of the inverter. Faults that may occur within the machine are not taken into account. Their diagnosis is abundantly treated in the literature [3].

One of the constraints for the monitor is to use as long as possible the already available information. It is based on the observation of patterns whose shape reveals a normal or faulty operation.

The monitoring system helps first to avoid manual procedures (potentially dangerous due to an electric hazard); second,

\footnotetext{
Manuscript received January 21, 2004; revised May 27, 2004. Paper no. TEC00008-2004.

D. Diallo is with the Laboratoire de Génie Electrique de Paris (LGEP), University of Paris XI, Gif-Sur-Yvette 91192, France (e-mail: ddiallo@ieee.org).

M.E.H. Benbouzid is with the Laboratoire d Ingénierie Mécanique et Electrique (LIME), Electrical Engineering Department, University of Western Brittany, Brest Cedex 29231, France (e-mail: m.benbouzid@ieee.org).

D. Hamad is with the University of Littoral Côte d Opale, Calais 62228, France.

X. Pierres is with the Institut Universitaire Professionalisé Génie Electrique et Informatique Industrielle (IUP GEII), University of Picardie Jules Verne, Amiens 80000, France.

Digital Object Identifier 10.1109/TEC.2005.847961
}

to keep the operating points over a certain amount of time; and third, to launch the diagnosis process as soon as an abnormal behavior appears. This makes it a useful tool for the maintenance team in reducing time to repair and in evaluating life expectancy of the power-electronic devices depending on the stress levels (e.g., thermal and mechanical) and on the original safety area for each device. Moreover, the monitoring is expected to reduce the production cost in industrial processes where downtime cost may be prohibitive and to keep available (client-oriented object) all of the data related to production conditions. In EV and $\mathrm{HEV}$, the monitoring is the first stage of the fault-tolerant control strategy, which has to ensure a limp-back operation rather than no operation at the onset of faults.

Three methods are mainly used in fault detection and diagnosis: model-based techniques, expert systems, and artificial neural networks (ANNs). Model-based techniques are very outstanding if an accurate model of the process can be obtained [4]-[6]. In an induction motor drive, an accurate model of the whole system is difficult to obtain. The inverter model (including snubber capacitance and balance resistors) is not only hard to obtain but is also inaccurate due to component values, parasitic components, and unavoidable assumptions and limitations. Therefore methods, which do not require model knowledge, are of great interest. Expert systems usually dedicated to big systems are useful if minor modifications are made in the process and above all, assume the existence of an expert to build the rules and the reasoning tree [7], [8]. The introduction of artificial intelligence methods (fuzzy logic and ANNs) is a step forward to more flexibility as there is no need for a model but also no need for expert knowledge [9], [10]. The accuracy of these methods depends upon the initial training data in healthy and faulty conditions. Nevertheless, this is not a major drawback in this case because reliable simulation tools exist that can furnish appropriate data.

This paper is devoted to fault detection and diagnosis in an induction motor drive using current sensors. The use of a time-average value allows distinguishing a faulty case from a transient overload. Moreover, the building of a healthy domain based on averaged experimental values helps to distinguish faults in the inverter from those of the machine. In Section II, a simplified analysis of the faulty drive is made to introduce the current pattern method [11], [12] and a spectral analysis of the measured electromagnetic (EM) torque is conducted. In Section III, fault detection and diagnosis in the high-power process by pattern comparison is presented. In Section IV, the building of the healthy operation area is made for low-power applications 


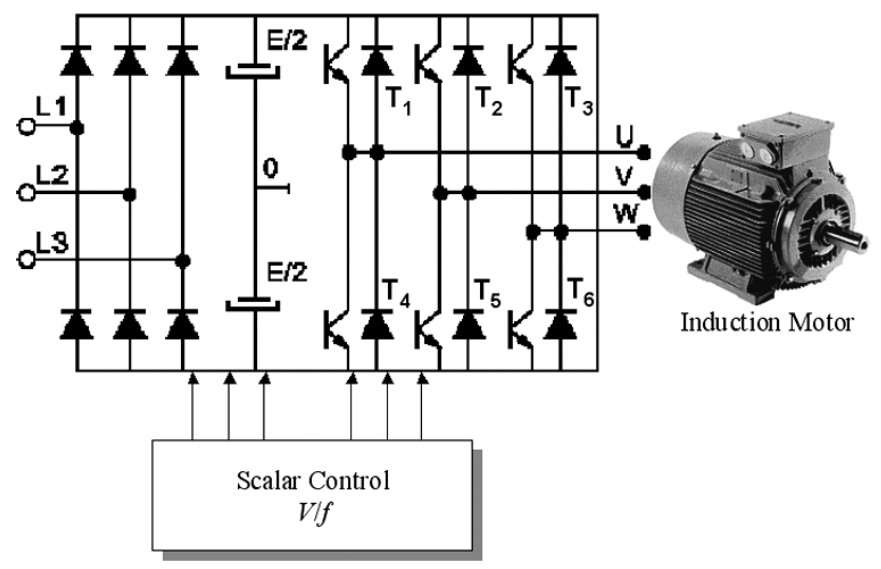

Fig. 1. Voltage-fed induction motor.

where only fault detection is required. The detection is instantaneous as it relies upon a single comparison. In Section V, the experimental bench is presented and the simulated experimental results are shown. Section VI is devoted to the conclusion.

\section{Electromechanical ANALYsis of a FAULTy Drive}

\section{A. Current Pattern Observation}

An open-loop volts/Hertz control is assumed for the drive as shown in Fig. 1. Only two current sensors are used and a mechanical one is not considered. The goal is not the study of the drive performances, so a closed loop is not assumed.

In this paper, the standard stationary reference frame $\alpha-\beta$ is used to evaluate the stator current pattern evolution when abnormal conditions occur in the inverter. In a three-phase inverter, the short circuit of a switching device is not studied because the protection system (e.g., input fuses, circuit breaker) designed conservatively stops the whole system immediately more efficiently than any other technique.

In healthy and ideal conditions, the stator current pattern in the Concordia reference frame is a circle with a constant radius in steady-state. The synchronous rotating frame (Park components) is not considered, as it requires the calculation or the estimation of the frame angle. When a fault occurs in the electronic circuit of a switching device leading to a misfiring, the stator current pattern is biased in such a direction that allows the fault diagnosis. The asymmetry in the output voltage creates a dc component which introduces in the sinusoidal current, a dc component whose sign indicates the bias direction [13]. Fig. 2 shows the simulated pattern in case of $T_{1}$ intermittent misfiring of 4-ms duration. Due to the pulsewidth modulation (PWM), the locus is obviously not a circle. The other patterns in case of misfiring are easily obtained by rotating the previous pattern of $120^{\circ}$. This fact is clearly illustrated by Fig. 3 where the vector current trajectory is shown before and after $T_{2}$ misfiring.

\section{B. Torque Analysis}

With the sine-triangle PWM and a high modulation index denoted $m$, the spectral analysis of phase voltages reveals some harmonics of ranks

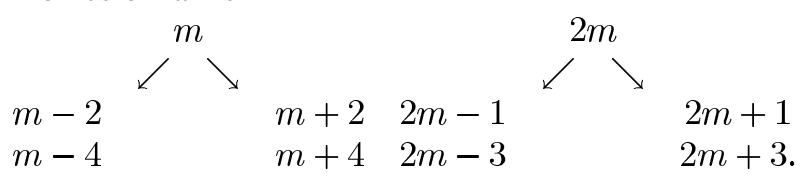

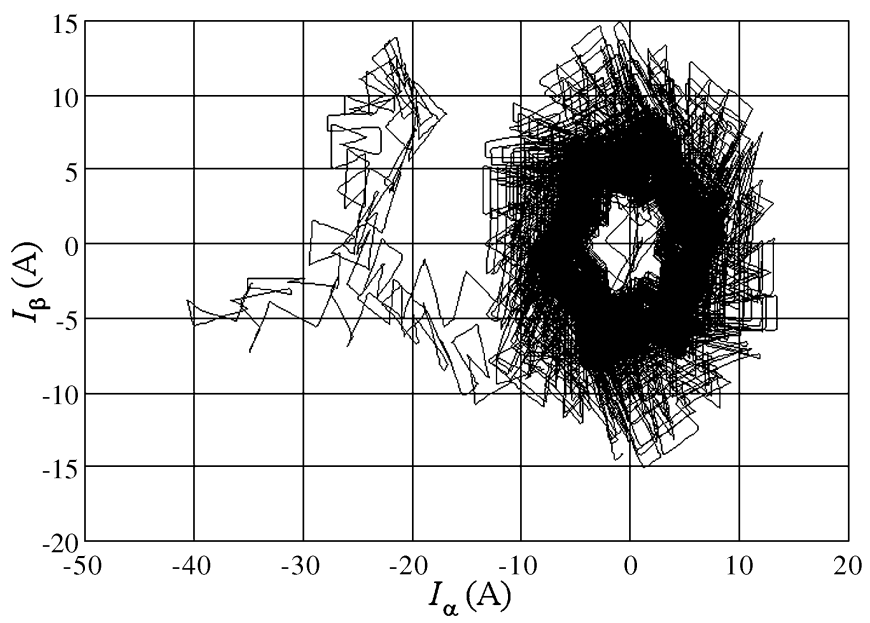

Fig. 2. Current pattern in case of $T_{1}$ misfiring.

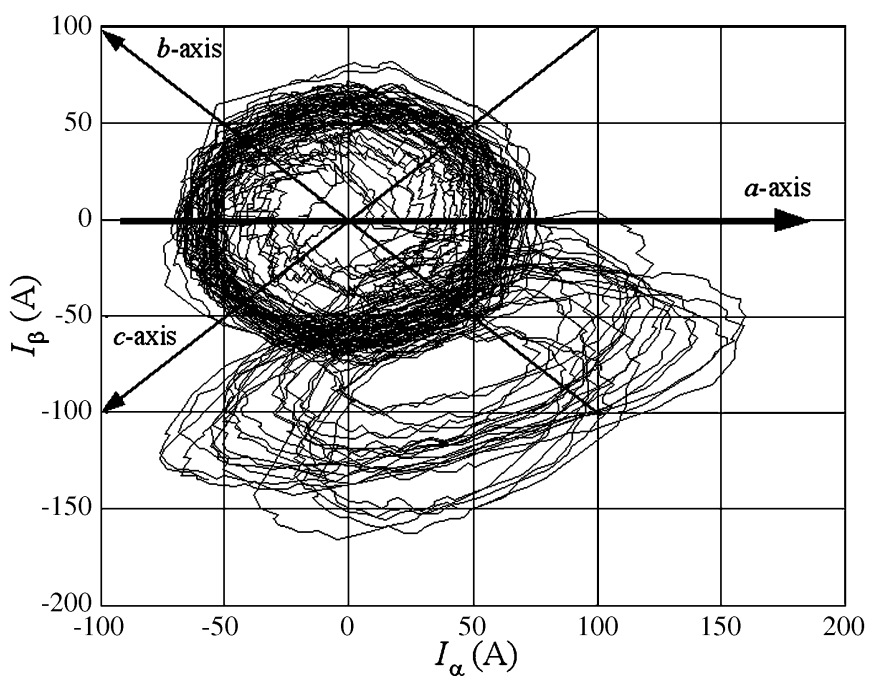

Fig. 3. Current pattern in case of $T_{2}$ misfiring.

In general, positive and negative alternations are symmetric so there are no even harmonics and, moreover, with a balanced load, $3 k$ harmonics are canceled. The remaining voltage harmonics generate currents that produce flux harmonics in the stator windings.

A single-phase approach with an equivalent circuit for each harmonic (the magnetization branch is neglected) shows that the resultant torque is the sum of:

- torque dc component due to the dc current and flux components and also to the current and flux harmonics components having the same rank;

- torque harmonics due to the interaction between current components (fundamental and harmonics) and stator flux components (fundamental and harmonics).

During normal operation, the torque contains $6 k f_{s}$ harmonic components where $k=1,2,3, \ldots$ and $f_{s}$ are the fundamental frequency. Except in the low-speed region, they have little impact on the mechanical parts. But when a misfiring occurs, a dissymmetry appears in the voltage. Therefore, the spectral content is wider including a dc component and even harmonics. Using the equivalent circuit theory, one can see that the resultant torque will contain a dc component and low-frequency components including the fundamental. This analysis is confirmed by the following curves (Fig. 4) showing the measured EM torque 


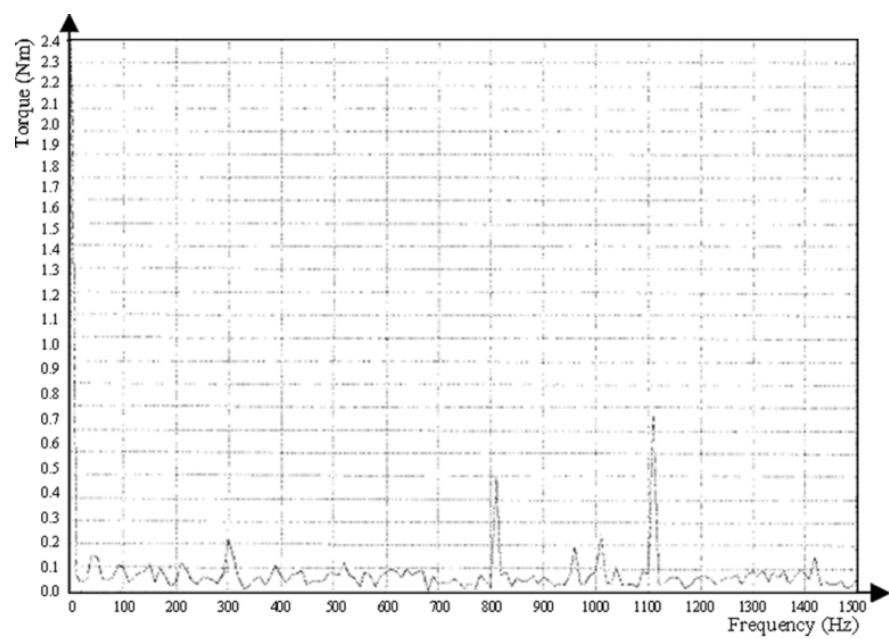

(a)

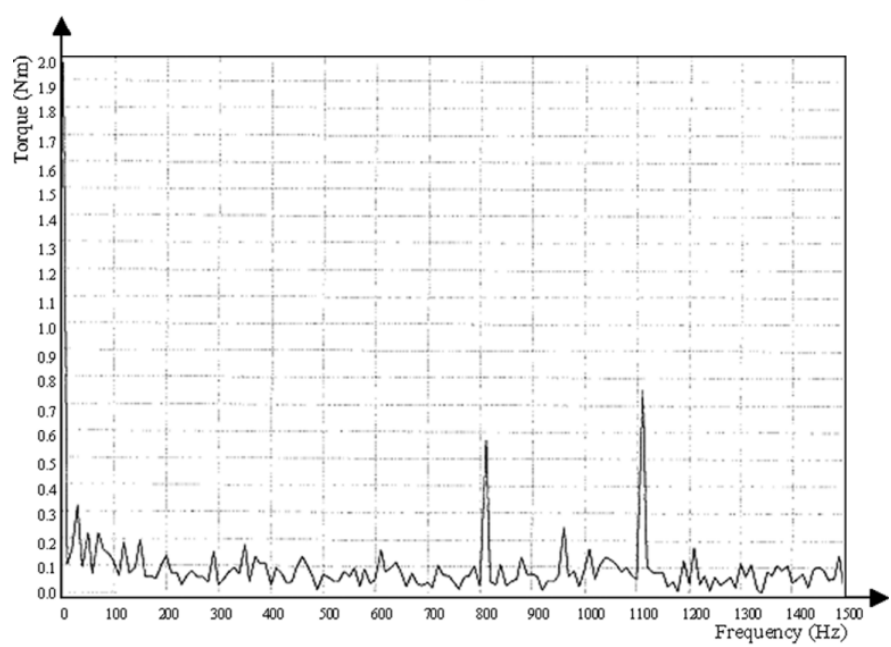

(b)

Fig. 4. Induction motor measured EM torque spectral content. (a) Healthy inverter. (b) Faulty inverter.

spectral content. It can be seen when a fault occurs, the low-frequency components at 25,50 , and $70 \mathrm{~Hz}$ are responsible for the mechanical constraints. The high-frequency components due to the PWM are filtered by the mechanical bandwidth.

These faults reduce the process components' (electrical and mechanical) lifetime because they generate important transitory constraints that are not easily measurable or detectable. Premature wear of bearings and shafts may result in unpredictable breakdowns [3].

\section{HIGH-POWER APPLICATION}

In high-power applications, the localization becomes crucial. The knowledge-based analytical approach [14] is interesting but not robust enough to manage the scattering of data points around the ideal contour.

The probabilistic approach is more powerful in the classifying process. If a normal law is assumed, the probability is

$$
p(I)=\frac{1}{2 \pi \sigma_{0}^{2}} \exp \left(-\frac{\|I\|^{2}}{2 \sigma_{0}^{2}}\right)
$$

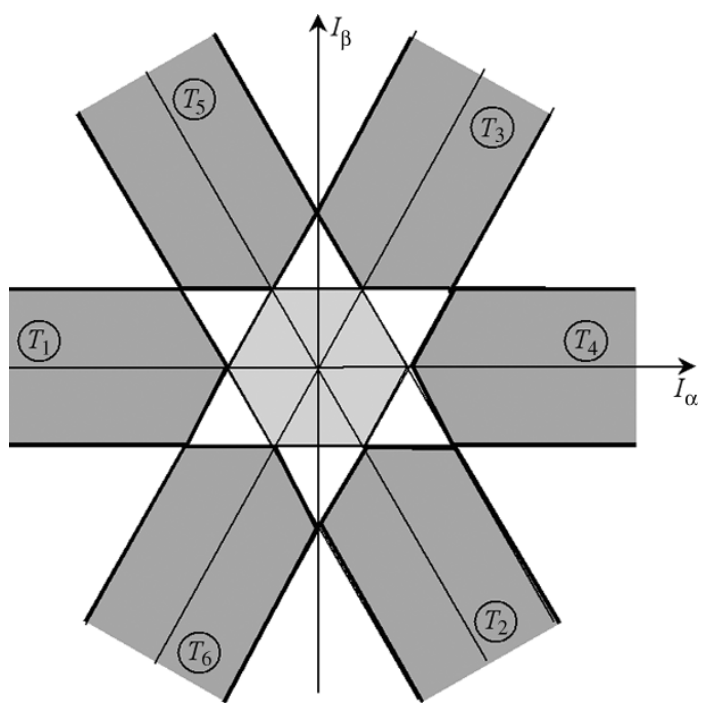

Fig. 5. Faults detection and diagnosis space.

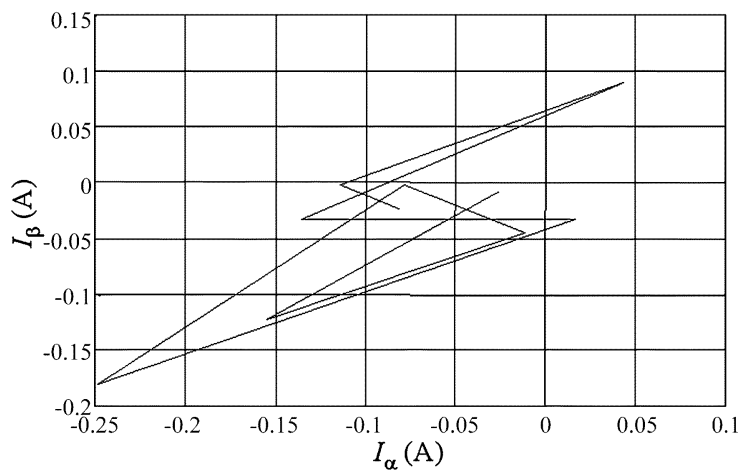

Fig. 6. Concordia pattern of the average current vector.

where $I$ is the mean current vector. The standard deviation $(0$ depending on the maximum offset current is set so as the probability of a false alarm is equal to $0.3 \%$.

The circle inside the hexagon of the space of localization showed in Fig. 5, has a radius $R$ which is defined as

$$
\|I\|^{2}=2 \sigma_{0}^{2} \ln \left(2 \pi \sigma_{0}^{2} p_{0}\right)=R^{2}
$$

where $p_{0}$ is the probability threshold of the healthy domain boundary. The thick lines represent the boundaries of the domains.

For example, $i_{\beta}=\sqrt{3} i_{\alpha} \pm i_{0}$ for $T_{3}$.

The centered hexagon defines the healthy domain. If a misfiring occurs, the pattern moves along one of the six directions.

If the conditions were ideal (pure sinusoidal supply), the average contour would have been a point. In reality, because of the PWM and the inherent imperfections, it is a set of points with low amplitude as can be seen in Fig. 6 .

The fault detection and algorithm works in the Concordia $\alpha-$ $\beta$ stator reference frame as it is described below.

- Calculation of the mean current vector and comparison of its module with the radius $R$.

- If a faulty condition is detected, the module of the mean current vector is calculated in each sector by an appropriate rotation of $\pi / 3$. 


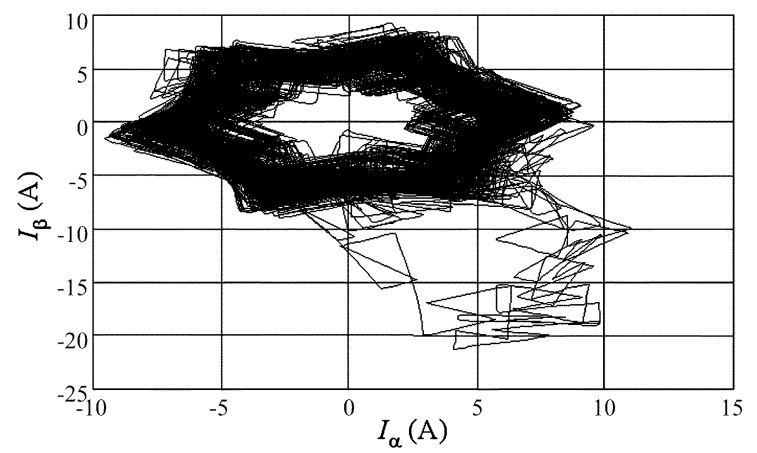

Fig. 7. Concordia pattern during intermittent misfiring of $T_{2}$.

- The faulty switch is identified depending upon the direction of the greatest module.

- A Boolean $S_{i}$ for each switching device is generated: 0 for healthy condition and 1 when abnormal conditions appear. A reliability coefficient can be calculated to ensure the diagnosis result.

We have chosen to separate the tasks of fault detection and fault diagnosis to reduce the decision time and to avoid the need of a pattern for each switch.

Fig. 7 shows the direction in which the Concordia pattern moves at the onset of the intermittent fault (four periods of PWM). The result of the algorithm is as follows:

\begin{tabular}{|c|c|c|c|c|c|}
\hline$T_{1}$ & $T_{2}$ & $T_{3}$ & $T_{4}$ & $T_{5}$ & $T_{6}$ \\
\hline 0 & $\mathbf{1}$ & 0 & 0 & 0 & 0 \\
\hline
\end{tabular}

\section{LOW-POWER APPLICATION}

In low-power applications $(<1-\mathrm{kW})$, fault diagnosis is not required as the power module substitution is of lower cost than a repair. Therefore, the key point is to detect abnormal conditions. The monitoring system here is devoted to split the process domain into two classes: normal and faulty. This is done by a radial basis functions (RBF) neural network trained by a set of data including all of the load conditions. This classification technique [15], [16] takes into account all of the uncertainties of the process by means of the used database. The network has an evolving architecture with three layers: an input layer with the stator current mean vector components $\left(I_{\alpha}, I_{\beta}\right)$, a hidden layer, and an output layer with a neuron which calculates the probability density depending on the distribution of the training database.

The probability density is a weighted sum of activation functions $G_{k}\left(I, \mu_{k}, \sigma\right)$.

$$
P(I)=\sum_{k=1}^{K} \omega_{k} G_{k}\left(I, \mu_{k}, \sigma\right) .
$$

The weights are defined as follows:

$$
\omega_{k}=\frac{G_{k}}{\sum_{l=1}^{K} G_{l}} .
$$

(b)

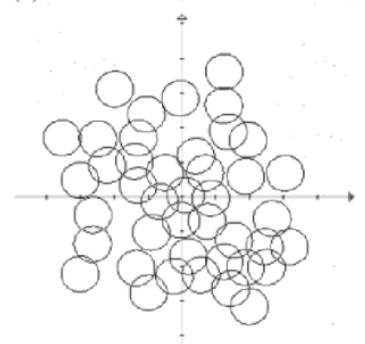

(d)

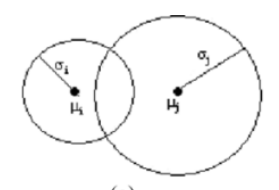

(a)

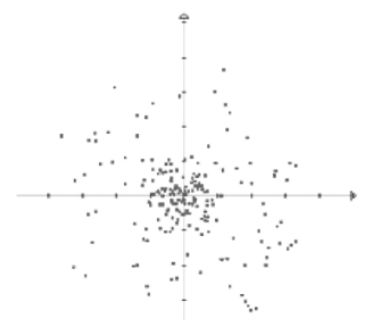

(c)
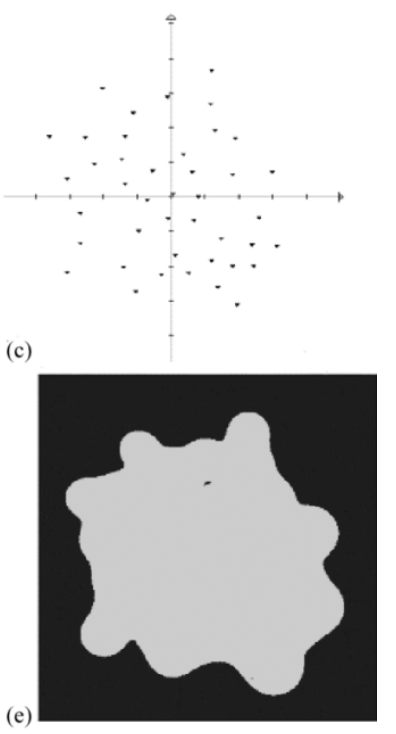

Fig. 8. Definition of the healthy domain. (a) Influence areas of two related neurons. (b) Training database. (c) Centers of the circles. (d) Building of the circles. (e) Healthy domain.

All of the hidden neurons have activation functions of Gaussian type defined as

$$
G_{k}\left(I, \mu_{k}, \sigma\right)=\frac{1}{2 \pi \sigma^{2}} \exp \left(\frac{-1}{2 \sigma^{2}}\left(I-\mu_{k}\right)^{T}\left(I-\mu_{k}\right)\right) .
$$

The receptive field or activation field of the Gaussian function is defined by the following equation:

$$
\left(I-\mu_{k}\right)^{T}\left(I-\mu_{k}\right)=\sigma^{2} .
$$

The classical approach to estimate the parameters of the probability density is to use the estimation maximization (EM) algorithm [17]. However, the algorithm is slow and requires a starting initialization point close to the optimum. Moreover, it assumes that the number of Gaussian functions is fixed. We propose an algorithm inspired from a reduced coulomb energy (RCE) classifier approach to determine the probability density parameters [18].

In a two-dimensional (2-D) system, receptive fields are circles $C_{k}$ of center $\mu_{k}$ and radius $\sigma$ [Fig. 8(a)]. Each circle is associated with one of the hidden neurons in the network. During the detection process, each set of experimental points must be within a receptive field. The challenge is to build the network (optimal number of hidden neuron) so as to make the monitoring system efficient, which means that the receptive fields must be built accurately enough from the training data. The receptive fields are obtained from an RCE algorithm. The radius $\sigma$ is chosen under different constraints: i) the activation areas cover the training points to allow a smooth fit of the desired network outputs; and ii) the radius must be kept at a minimum to tighten the receptive field to the training data it represents so as to have a high activation capability near the center. From 
a training database of 200 points, we have obtained a network with $\sigma=5.158$ and 45 neurons in the hidden layer. Fig. 8 summarizes the principle and shows the healthy operation area of the process. The diagnosis consists of calculating, for a set of points, the probability density of belonging to the predefined area.

The proposed algorithm is composed of two steps: ii) learning of the receptive field centers; and ii) adjustment of the corresponding radius. We start with a number of hidden units null. We fix the radius of the receptive field $\sigma$ that will be optimized in the second step.

\section{A. Learning of the Receptive Field Centers (Algorithm)}
1) Fix: The number of Gaussian func- tions to 1 and the radius of the re- ceptive fields to $\sigma_{\min }$.
2) Start: randomly select a point from the learning data base $n=1$.
3) Present: If all points are pre- sented, go to 5, else present a point $I_{n}$.
4) Assign: If the point $\left(I_{n}\right)$ is in the receptive field of index $i$, then
- Assign the point to this recep- tive field
- Else create a receptive field centered on this point $I_{n}$
- $n=n+1$, go to 3 .
5) Adapt: Compute the new center $\mu_{i}$ of each receptive field as the gravity center of its assigned points.
6) Prune: Prune Gaussian units that do not contain any point.
7) Test: If the centers do not move then stop, else go to 2 .

At the end of centers estimation, compute the weights $\omega_{i}$ using the equation

$$
\omega_{k}=\frac{\sum_{n=1}^{N} G\left(I_{n}\right)}{\sum_{j=1}^{M} \sum_{n=1}^{N} G_{j}\left(I_{n}\right)} .
$$

\section{B. Receptive Field Radius Adjustment}

In order to adjust the radius $\sigma$, we have used the cross validation technique. We split the database into two sets $U_{1}$ and $U_{2}$. We vary the radius $\sigma$ value in the domain $\left[\sigma_{\min }, \sigma_{\max }\right]$ with a fixed step. For each value of $\sigma$, a learning procedure of the receptive field centers is applied on $U_{1}$ and a validation procedure by likelihood computation is applied to $U_{2}$. And inversely, the learning procedure is applied to $U_{2}$ while the likelihood computation procedure is applied on $U_{1}$. For each value of $\sigma$, we compute the final likelihood sum $L=L_{1}+L_{2}$. The optimal value of $\sigma$ is the one which corresponds to the maximum of $L$ or the minimum of $-\operatorname{Ln}(L)$.

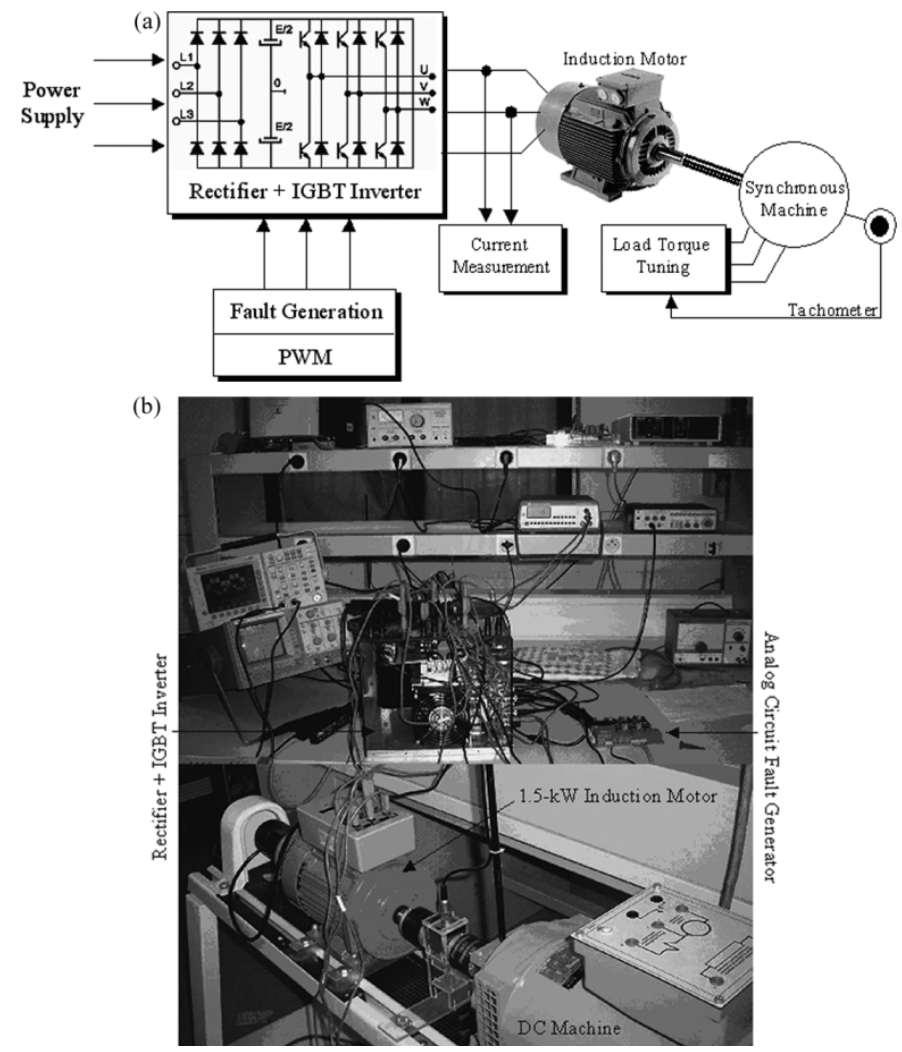

Fig. 9. Experimental setup.

\section{EXPERIMENTS}

Fig. 9a describes the experimental setup. The three-phase inverter is insulated-gate bipolar transistor (IGBT) based with a sinus-triangle PWM of which the carrier frequency is set to 1 $\mathrm{kHz}$. The fault is generated by an analog circuit, which can produce a variable duration fault, a variable fault numbers per period, and a manual switch to inhibit the fault generation.

The induction motor $(0.3 \mathrm{~kW}, 230 / 400 \mathrm{~V}, 1.47 / 0.85 \mathrm{~A}, 1380$ $\mathrm{r} / \mathrm{min}$ ) is coupled to a synchronous machine $(230 \mathrm{~V}, 2.5 \mathrm{~A}, 2000$ $\mathrm{r} / \mathrm{min}$ ) connected to an electronic drive to set the operating point. With a 2.5-Nm load torque, a misfiring of 3.3-ms duration every two periods is caused.

The second benchmark is composed of an induction motor $(1.5 \mathrm{~kW}, 230 / 400 \mathrm{~V}, 3.50 / 6.10 \mathrm{~A}, 1420 \mathrm{r} / \mathrm{min})$ coupled to a dc machine feeding a variable resistor (Fig. 9b). The misfiring time duration is adjusted to $3.5 \mathrm{~ms}$.

\section{A. Results for the 1.5-kW Induction Motor Drive}

The first step is the boundary definition for the fault detection and diagnosis space. The key point is the choice of the healthy domain radius to avoid false alarms but to also make the detection process reliable. The radius of the circle inside the hexagon of Fig. 5 is therefore defined for each machine as a percentage of the nominal current.

One can see in Fig. 10 that for both light and full-load cases, the average current vector patterns are comprised within the healthy domain. The healthy domain boundary is therefore correctly set.

1) Light-Load Case: When the machine is lightly loaded or is in no-load condition, the Concordia current vector patterns are 


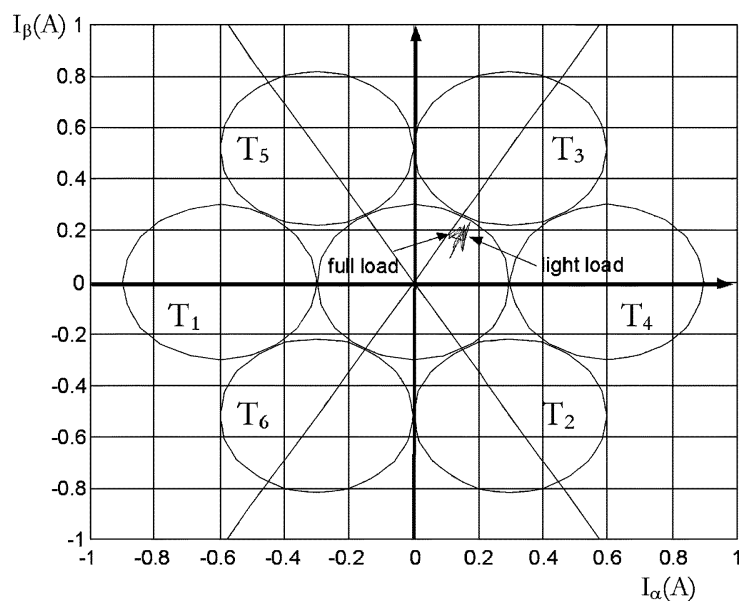

Fig. 10. Concordia average current vectors for light and full load in the healthy case.

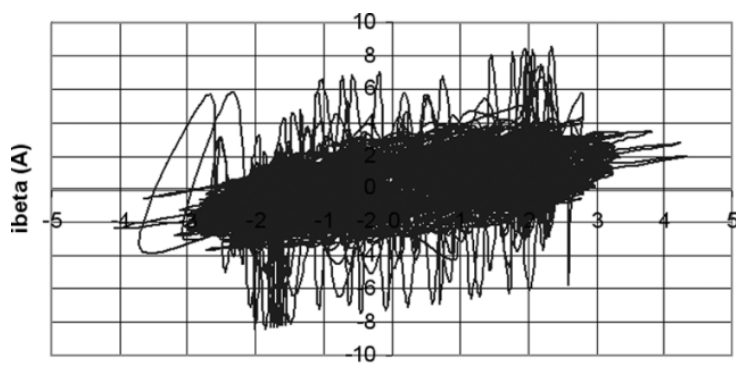

ialfa (A)

(a)

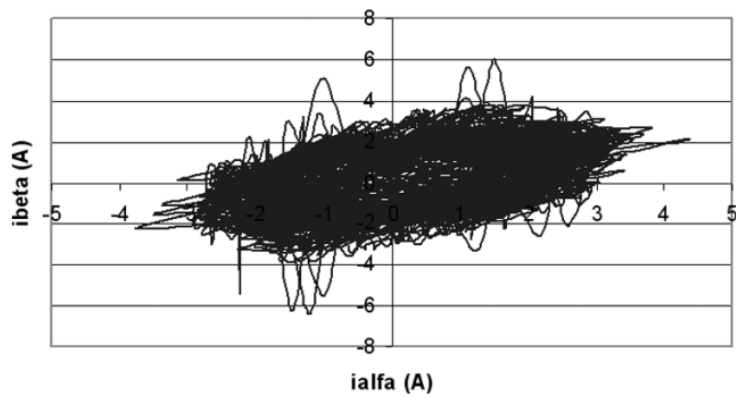

(b)

Fig. 11. Concordia current vector in light load case. (a) Healthy situation. (b) Faulty situation.

quite similar in healthy and faulty situations as can be seen in Fig. 11. Therefore, the use of the average current vector is here crucial to detect a fault occurrence. One can see in Fig. 12 that the average current vector (made of ten periods) moves slightly outside the healthy domain revealing a fault occurrence and the diagnosis process shows that the pattern moves along the horizontal axis revealing a misfiring of the switching power device $T_{4}$ (Fig. 1).

2) Full-Load Case: Fig. 13 shows the mains current at the onset of faults. The faulty phase is clearly put into evidence. When the machine is loaded, the Concordia current vector patterns are shown in Fig. 14 in healthy and faulty situations. When a fault occurs, as can be seen in Fig. 15, the pattern moves outside the healthy domain. It may first seem that the fault concerns either $T_{4}$ or $T_{3}$. But the deviation is more horizontal indicating that the misfiring concerns the switching power device $T_{4}$, which is confirmed by the algorithm. The diagnosis process

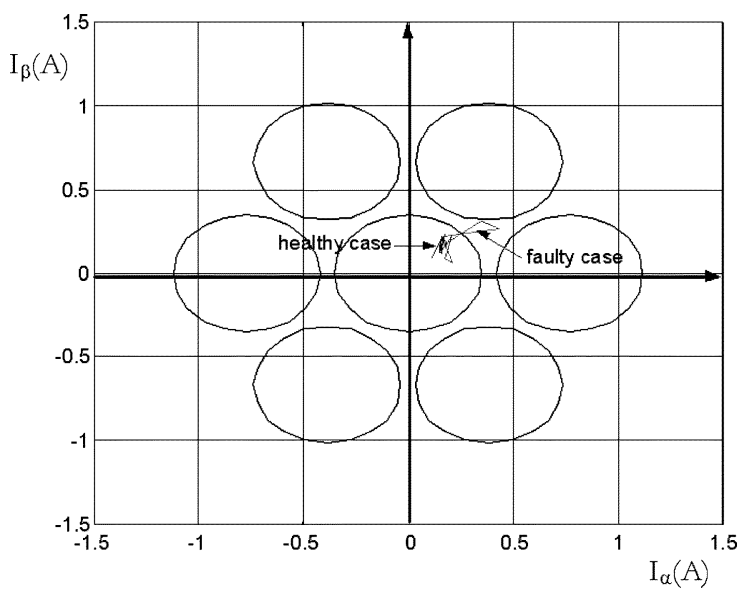

Fig. 12. Concordia average current vector for a light load in healthy and faulty cases.

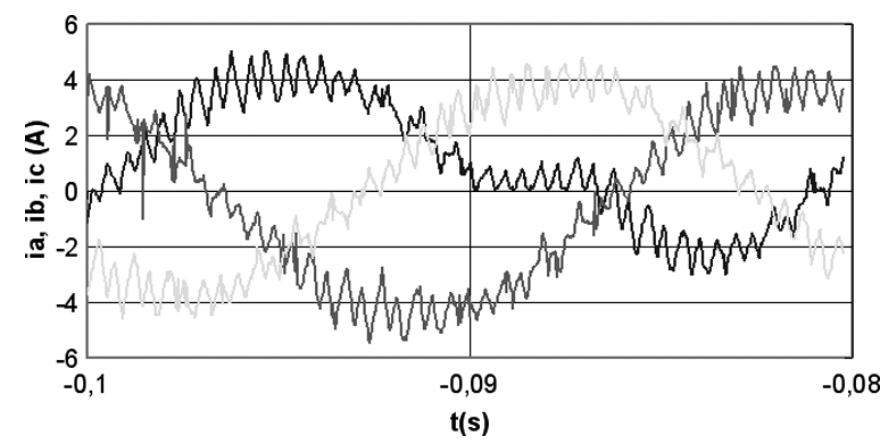

Fig. 13. Mains currents at the onset of fault.

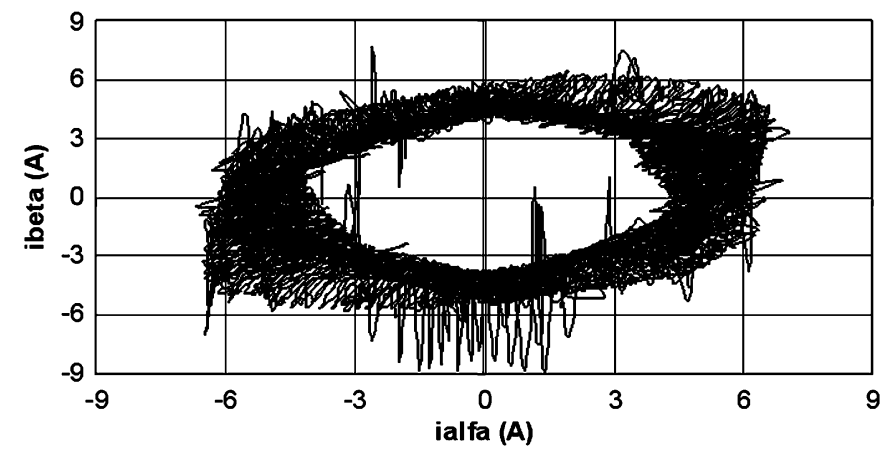

(a)

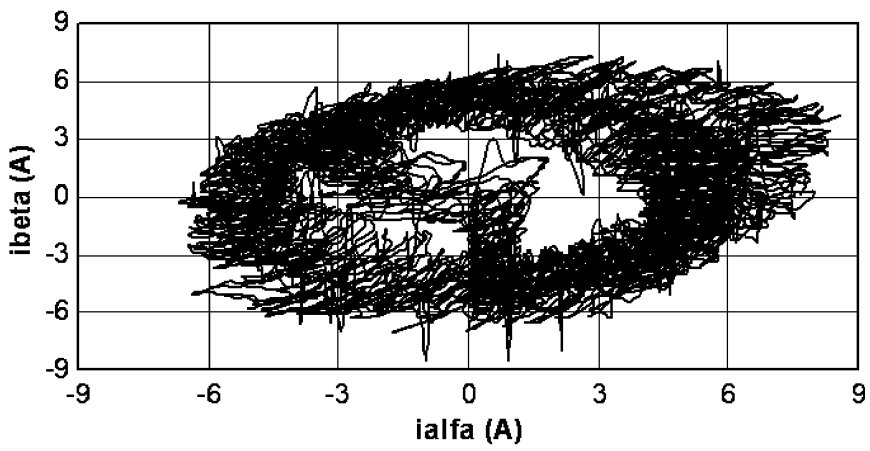

(b)

Fig. 14. Concordia current vector patterns. (a) Healthy situation. (b) Faulty situation.

is reliable and can also be confirmed by the average rate of the pattern that is less than $\sqrt{ } 3$ and can definitely eliminate the $T_{3}$ case. 


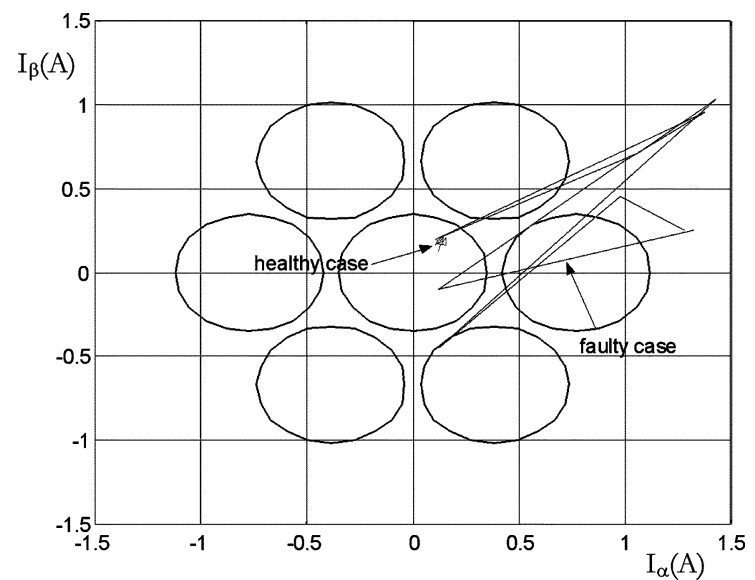

Fig. 15. Concordia average current vector for full load in healthy and faulty cases.

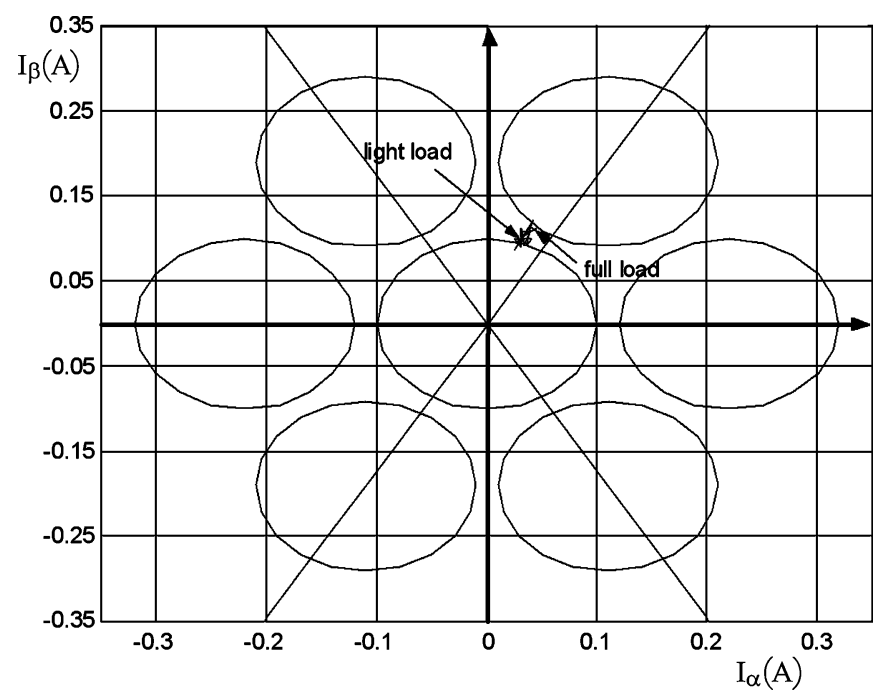

Fig. 16. Concordia average current vectors for light and full load in the healthy case.

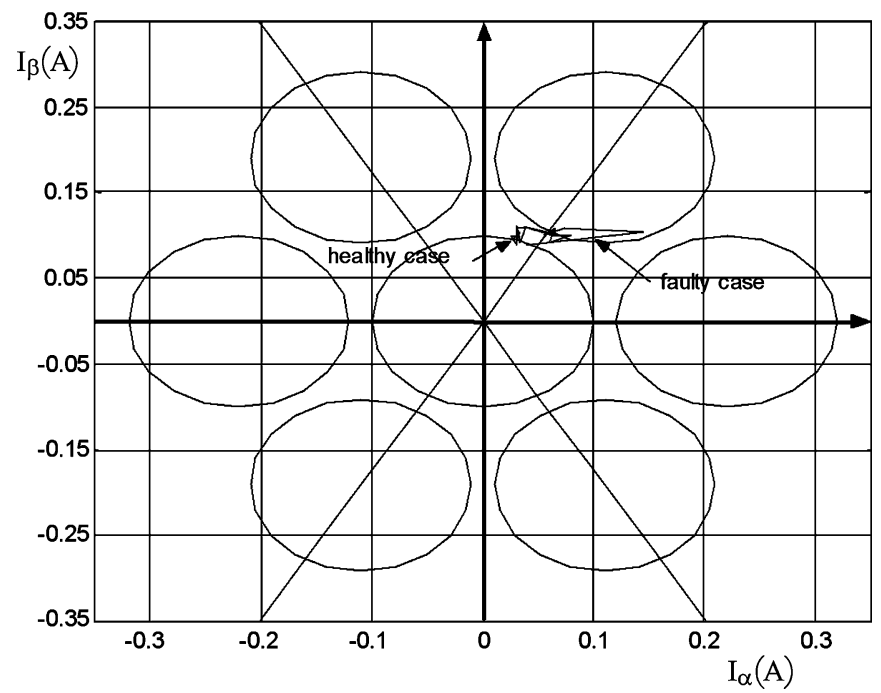

Fig. 17. Concordia average current vector for light load in healthy and faulty cases.

\section{B. Results for the 0.5-kW Induction Motor Drive}

As the machine is star connected, the radius of the healthy domain must be set in concordance with the mains current. One

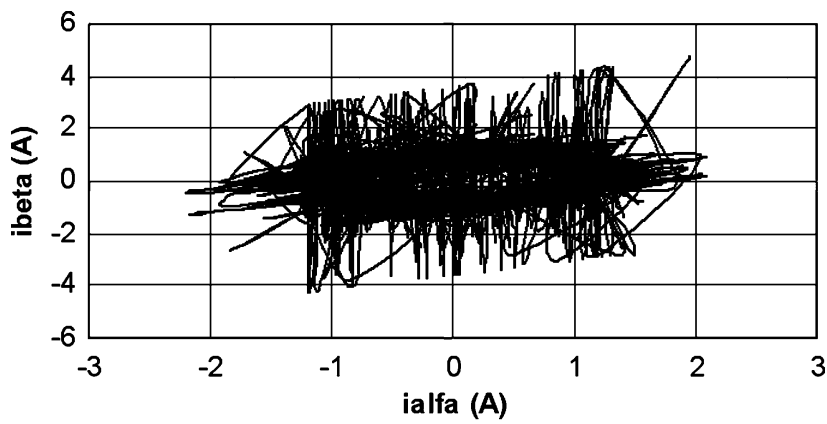

(a)

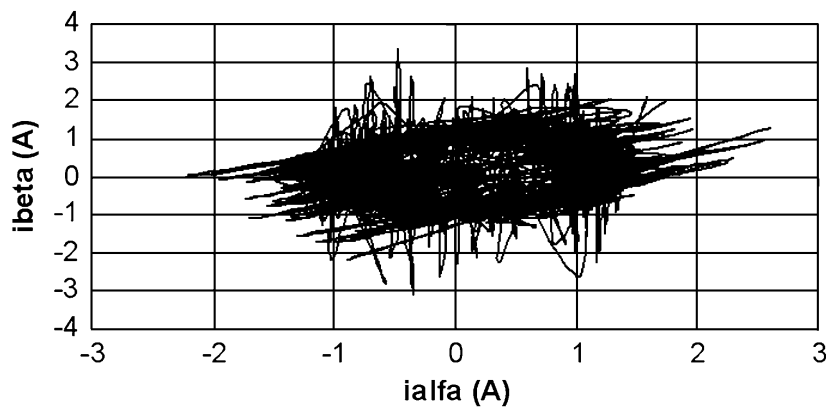

(b)

Fig. 18. Concordia current vector patterns in high-load conditions. (a) Healthy situation. (b) Faulty situation.

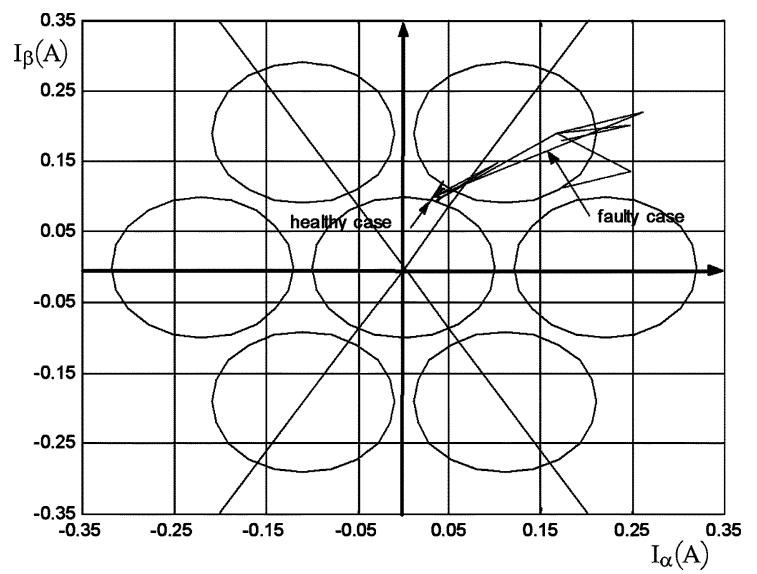

Fig. 19. Concordia average current vector for high load in healthy and faulty cases.

can see in Fig. 16 that for both light- and full-load cases, the average current vectors patterns are comprised within the healthy domain. Under the same boundary definition, we notice that the healthy domain definition is somehow difficult. False alarms may arise.

1) Light-Load Case: Under faulty conditions, the Concordia mean current vector shown in Fig. 17 reveals a lack of reliability.

2) Full-Load Case: When a fault occurs, as can be seen in Figs. 18 and 19, the pattern moves outside the healthy domain. It seems that the fault concerns $T_{3}$. Actually, the detection is a false alarm because the faulty device is $T_{4}$. For small power machines $(<0.5-\mathrm{kW})$, there is a lack of robustness in the healthy boundary definition. This may lead to false alarms. This example has been chosen to show that even so, the method is adaptive but it is more convenient to high-power applications. 
This is of great interest since the time to repair (which means that the process is stopped) is costly and, therefore, any help in detection and diagnosis will be cost-effective.

\section{CONCLUSION}

We have developed a method for fault detection and diagnosis of switching device misfiring in a voltage-fed PWM inverter induction motor drive. The method is based on the Concordia stator mean current pattern. Only two current sensors are used for simplicity and cost-effectiveness purposes. A fault detection and diagnosis space made with seven patterns is built with the stator Concordia mean current vector. One is dedicated to the healthy domain and the last six to each inverter switch. A probabilistic approach for the definition of the boundaries increases the robustness of the method against the uncertainties due to measurements and PWM. This is a crucial point to increase the method accuracy and also to avoid false alarms. When the average current vector pattern lies between two domains of the faults detection and diagnosis space, the robustness can be increased with the use of the average rate.

In high-power equipment where it is crucial to detect and to diagnose the inverter faulty switch, a simple algorithm compares the patterns and generates a Boolean indicating the faulty device. In low power application (less than $0.5 \mathrm{~kW}$ ) where only fault detection is required, a RBF evolving neural network architecture is used to build the healthy operation area. Furthermore, it can help to take into account the drive natural bias and can be updated to introduce the machine "natural wear." Simulated experimental results have shown the feasibility of the proposed approach.

\section{REFERENCES}

[1] D. Kastha et al., "Investigation of fault modes of voltage-fed inverter system for induction motor drive," IEEE Trans. Ind. Appl., vol. 30, no. 4, pp. 426-433, Jul./Aug. 1994.

[2] Z. Ye et al.. Simulation of Electrical faults of three phase induction motor drive system. presented at Proc. CD-ROM IEEE-PESC'01

[3] M. E. H. Benbouzid, "Bibliography on induction motors faults detection and diagnosis," IEEE Trans. Energy Convers., vol. 14, no. 4, pp. 1065-1074, Dec. 1999.

[4] S. B. Dolins et al., "A curve interpretation and diagnostic technique for industrial process," IEEE Trans. Ind. Appl., vol. 28, no. 1, pp. 261-267, Jan./Feb. 1992.

[5] R. Peuget et al., "Fault detection and isolation on a PWM inverter by knowledge-based model," IEEE Trans. Ind. Appl., vol. 34, no. 6, pp. 1318-1326, Nov./Dec. 1998.

[6] R. L. D. A. Ribeiro et al., "Fault detection of open-switch damage in voltage-fed PWM motor drive systems," IEEE Trans. Power Electron., vol. 18 , no. 2 , pp. 587-593, Mar. 2003.

[7] F. Filippetti et al., "An approach to knowledge representation about induction machine diagnostics in expert systems," in Proc. Int. Conf. Electrical Machines, Pisa, Italy, 1988, pp. 289-296.

[8] J. Sottile et al., "An overview of fault monitoring and diagnosis in mining equipment," IEEE Trans. Ind. Appl., vol. 30, no. 5, pp. 1326-1332, Sep./Oct. 1994.

[9] F. Filippetti et al., "Neural networks aided on-line diagnostics of induction motor rotor faults," IEEE Trans. Ind. Appl., vol. 31, no. 4, pp. 892-899, Jul./Aug. 1995.

[10] - "AI techniques in induction machines diagnosis including the speed ripple effect," IEEE Trans. Ind. Appl., vol. 34, no. 1, pp. 98-108, Jan./Feb. 1998.

[11] H. Nejjari et al., "Monitoring and diagnosis of induction motors electrical faults using a current Park's vector pattern learning approach," IEEE Trans. Ind. Appl., vol. 36, no. 3, pp. 730-735, May/Jun. 2000.

[12] A. M. S. Mendes et al.. Fault diagnosis in a rectifier-inverter system used in variable speed ac drives by the average current Park's vector approach. presented at Proc. CD ROM EPE
[13] K. S. Smith et al., "Real-time detection of intermittent misfiring in a voltage-fed PWM inverter induction-motor drive," IEEE Trans. Ind. Electron., vol. 44, no. 4, pp. 468-476, Aug. 1997.

[14] J. Milimonfared et al., "A novel approach for broken rotor bar detection in cage induction motors," IEEE Trans. Ind. Appl., vol. 35, no. 5, pp. 1000-1005, Sep./Oct. 1999.

[15] J. Leonard et al., "Radial basis function networks for classifying process faults," IEEE Contr. Syst., vol. 11, no. 3, pp. 31-38, Apr. 1991.

[16] S. Haykin, Neural Networks. A Comprehensive Foundation. Upper Saddle River, NJ: Prentice-Hall, 1999.

[17] S. J. Nowlan, "Maximum likelihood competitive learning," in Advances NIPS, vol. 2, 1990, pp. 574-582.

[18] M. J. Hudak, "RCE classifier: theory and practice," Int. J. Cybern. Syst., vol. 23, pp. 483-515, 1992.

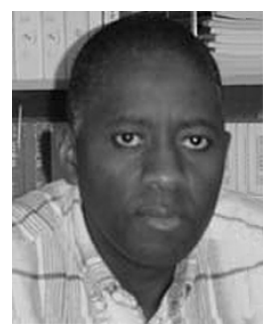

Demba Diallo (M'99) was born in Dakar, Senegal, in 1966. He received the M.Sc. and Ph.D. degrees in electrical and computer engineering from the $\mathrm{Na}$ tional Polytechnic Institute of Grenoble, Grenoble, France, in 1990 and 1993, respectively.

From 1994 to 1999, he was a Research Engineer with the Laboratoire d Electrotechnique de Grenoble, Grenoble, France, working on electrical drives and active filters (hardware and software). In 1999, he joined the University of Picardie Jules Verne, Amiens, France, as Associate Professor of Electrical Engineering. In 2004, he was an Associate Professor of Electrical Engineering with the IUT of Cachan, University of Paris XI, Gif-Sur-Yvette, France. He is also with the Laboratoire de Génie Electrique de Paris, Paris, France. His research includes advanced control techniques and diagnosis in the field of ac drives.

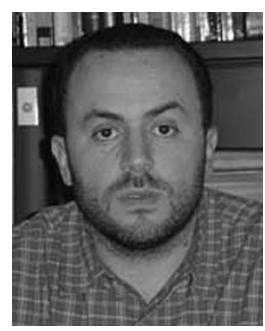

Mohamed El Hachemi Benbouzid (S'92-M'94SM'98) was born in Batna, Algeria, in 1968. He received the B.Sc. degree in electrical engineering from the University of Batna, Batna, Algeria, and the M.Sc. and Ph.D. degrees in electrical and computer engineering from the National Polytechnic Institute, Grenoble, France, in 1991 and 1994, respectively.

After graduation, he joined the University of Picardie Jules Verne, France, where he was an Associate Professor of Electrical and Computer Engineering at the Professional Institute of Amiens, Amiens, France. In 2000, he received the Habilitation à Diriger des Recherches degree from the University of Picardie Jules Verne. In 2004, he became Professor of Electrical Engineering, IUT of Brest, University of Western Brittany, Brest Cedex, France. His main research interests and experience include analysis, design, and control of electric machines, variable speed drives for traction and propulsion applications, and fault diagnosis of electric machines.

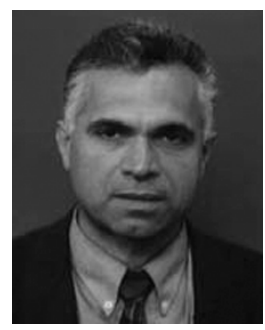

Denis Hamad received the Habilitation à Diriger des Recherches degree in physics sciences from the University of Lille I, Lille, France, in 1997.

Currently, he is a Full Professor in Automatic Control and Computer Science, University du Littoral Côte d'Opale, Calais, France. Previously, he was Professor at the University of Picardie "Jules Verne," Amiens, France, from 1998 to 2002, and Associate Professor at the University of Lille I, Lille, France. His research interests involve neural networks, pattern recognition, exploratory data analysis, and image processing.

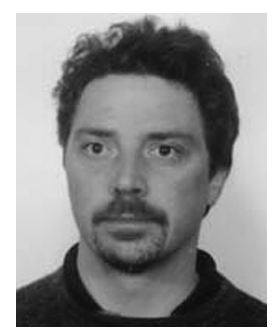

Xavier Pierre was born in France. He received the M.Sc. and Ph.D. degrees in electrical and computer engineering from the University of Sciences and Techniques, Lille, France, in 1991 and 1994, respectively.

Currently, he is an Associate Professor of Electrical Engineering, Professional Institute of Amiens (IUP GEII), University of Picardie "Jules Verne," Amiens, France. His research interests include high-power rectifiers. 